\title{
AC 2007-2163: DESIGN OF A THERMAL SYSTEMS COURSE
}

Jesse Maddren, California Polytechnic State University

Jesse Maddren is Associate Professor in the Mechanical Engineering Department at California Polytechnic State University in San Luis Obispo, CA. 


\title{
Design of a Thermal Systems Course
}

\begin{abstract}
Many mechanical engineering programs offer thermal systems design as either a required or elective class, typically during the senior year. The course integrates the subjects of thermodynamics, fluid mechanics and heat transfer in the design of a system. There are a few different thermal systems design textbooks available. The topics that are most commonly included are: the design process, numerical modeling and simulation, economics, optimization, in addition to topics such as piping system design, heat exchangers, etc.
\end{abstract}

The paper describes the changes made in a senior level thermal systems design course over a period of approximately seven years. The course is taught in the lecture/laboratory mode and the principal changes were made in the laboratory. In the past, the lab component was a computational lab that solved individual weekly problems using Engineering Equation Solver (EES). EES is a commonly used software application for solving thermal systems problems, such as system simulation problems with several unknowns and optimization problems with one or more independent design variables. Over the years, the laboratory has been used to test other types of projects including longer term projects that are more applied, such as the design of a solar domestic hot water system for a dormitory and the design and construction of small thermal systems, such as a soft drink cooler.

This paper presents a survey of how thermal systems design is taught in mechanical engineering programs. The paper also outlines the author's personal experiences with teaching thermal systems design, what has worked and what has not worked.

\section{Background}

A brief investigation into different mechanical engineering programs across the United States shows that many programs offer a thermal systems design course. For some programs, thermal systems design is a required course, and for others it is required for a particular concentration or offered as a technical elective. The Accreditation Board for Engineering and Technology (ABET) stipulates that a mechanical engineering program must "demonstrate that graduates have the ability to work professionally in both thermal and mechanical systems areas including the design and realization of such systems." While a thermal systems design course should satisfy this requirement concerning thermal systems, surely other classes could incorporate a component of thermal systems design and therefore satisfy the criteria. Therefore, a program would not be required to have a thermal systems design course required for all students.

Thermal systems design has been described as a "hodgepodge" by other instructors ${ }^{1}$ who teach it and I don't know if I would disagree. Machine design seems to follow a logical progression from statics, to dynamics and strength of materials, to machine components and finally to mechanical design. Thermal systems design takes the subjects of thermodynamics, heat transfer and fluid mechanics, most of which are taught in multiple courses and are taught concurrently and tries to integrate them together in a culminating experience. Additional subjects such as economics and 
optimization are also brought in to help explain design decisions. In addition, while the machine design track is typically focused on hands-on design tasks, the thermal system design courses tend to focus on analysis tasks that support design but maybe are not as applied.

A brief review of different textbooks on thermal systems design is included in Table 1. The table shows the relative percentage of each subject in comparison to the rest of the material in the book. The topics that are most commonly included are: the design process, review (thermodynamics, heat transfer and fluid mechanics), system design, modeling and simulation, numerical modeling, economics, optimization, in addition to topics such as piping system design and heat exchangers. The last row in the table indicates whether the book is in print. This evaluation was based on checking the web site of the last known publisher to see if the book was listed. Although a majority of the books are out of print, the table represents a good overview of what subjects have been taught in thermal systems design classes.

Table 1. Summary of textbooks on thermal system design*

\begin{tabular}{|c|c|c|c|c|c|c|c|}
\hline Topic & 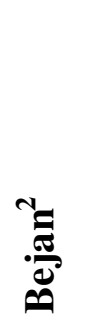 & 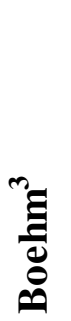 & $\begin{array}{l}\nabla_{0} \\
\stackrel{\theta 0}{g} \\
\stackrel{\theta}{\theta}\end{array}$ & 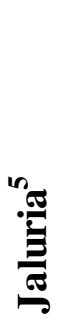 & 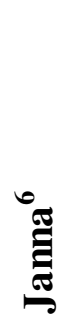 & 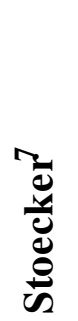 & 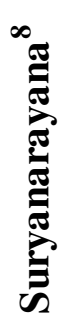 \\
\hline Introduction & & & & 4 & 2 & & 3 \\
\hline Design Process & 7 & 7 & & 17 & 3 & 2 & 3 \\
\hline Ethics & & & & & & & 8 \\
\hline Review & 26 & & & & 15 & & 32 \\
\hline Component Design & 19 & & & & & & \\
\hline System Design & & & & 14 & & 3 & 30 \\
\hline Modeling and Simulation & 2 & 5 & 7 & 13 & & 36 & 7 \\
\hline Economics & 26 & 19 & & 7 & & 5 & 7 \\
\hline Optimization & 9 & 14 & & 19 & & 22 & \\
\hline Availability/Exergy & 11 & 13 & & & & & \\
\hline Heat Exchangers & & 13 & 35 & & 26 & & \\
\hline Fluid Flow Systems & & 11 & 47 & & 44 & & \\
\hline Numerical Modeling & & 18 & 11 & 20 & & 28 & \\
\hline Other & & & & 6 & 10 & 4 & 10 \\
\hline In print & Yes & No & Yes & No & Yes & No & $\mathrm{No}$ \\
\hline
\end{tabular}

* The numbers in the table represent the relative percentages of each subject in comparison to the rest of the material in the book.

Many times, a thermal systems design class is taught in the lecture/lab mode. The laboratory is an opportunity to spend more time on active learning exercises that reinforce the lecture 
examples and give the students opportunities to go through the design process. A review of the literature found that instructors use both paper design projects and hardware design projects in the lab. The end result of a paper design project is a project report or paper summary of the design, whereas a hardware design project has the students design, build and test their design. Both types of design projects incorporate a significant amount of analysis, usually computer intensive. Certainly, with recent advances in computing power and software the nature of thermal systems design courses has changed. Where previously, maybe ten years ago or more, students might be required to write code to solve a set of non-linear equations, they are more likely now to use one of the many packaged software applications that can do that and a wide variety of other tasks.

In 1998, Taylor and Hodge ${ }^{9}$ discussed the implementation of MathCad in an energy systems design course. This was a change compared to students writing their own code to solve required problems. The authors reported that the solution approach resulted in more emphasis on engineering and less on programming and was deemed a success.

Hodge and Steele ${ }^{10}$, in 2001, reported on a survey conducted of seventy-three mechanical engineering programs in the United States. The survey was undertaken to determine the usage of structured programming languages (such as C, FORTRAN and BASIC) and equation solving applications (such as EES, TKSolver, MathCad, Matlab, etc). The survey showed that approximately three-fourths of the universities required a programming course but only one-third of those used programming in two or more subsequent required courses. More than three-fourths of the programs surveyed utilized some sort of commercial software for solving equations and a majority of the respondents indicated that they required extensive use of the application in subsequent courses. Therefore, it appears that the commercial software applications had more utility in problem solving.

Genik and Somerton ${ }^{1}$ describe their work in a senior level capstone course in thermal engineering. "Among the topics covered were power system analysis, refrigeration systems, psychrometrics, combustion, heat exchangers, and numerical conduction. Though the list of topics may seem to be a hodgepodge, it is somewhat reflective of the eclectic nature of engineering." To combat the perception of this "hodgepodge" of subjects they designed a set of projects for a semester long course, which were all focused on a common theme: the analysis of a land based gas turbine system. The projects were all paper designs and had a strong orientation towards analysis and computer modeling, with the students either writing their own code or using a packaged software application. The authors reported that the common theme brought some cohesion to these seemingly disparate subjects and enhanced student learning.

Wedekind and Kobus ${ }^{11}$ reported on their experience teaching a thermal systems design class. The class was a lecture/lab class and while the lecture reviewed topics in thermodynamics, fluid mechanics and thermal energy transport, the laboratory was focused on the design, construction and testing of a component or system. Students were evaluated with respect to Bloom's taxonomy. The homework and quizzes in the lecture were geared to test the students' knowledge and comprehension and their ability to apply this knowledge to solve engineering problems. The laboratory design project was structured to test the students' ability to analyze design problems, synthesize solutions and evaluate and therefore optimize their design. The students were required 
to design and test a thermal energy recuperator, or regenerative heat exchanger. Specifications were given for the project: flow rates, temperatures, cost information and the students were tasked with designing and building a heat exchanger. Raw materials and tools were provided for the construction of the heat exchanger and a test apparatus was provided for the students to test their designs with respect to the project objectives. The project was performed over the final five weeks of the semester in teams of three to four students. It was noted that this was the first time that many of the students had been required to build a prototype of their design and the student response was overwhelmingly positive.

\section{Thermal System Design at Cal Poly: Lecture}

I have taught the thermal systems design course at Cal Poly for the past seven years. Cal Poly is on the quarter system and the course is taught every quarter. Prior to this course, the students have taken two quarters of thermodynamics, two quarters of fluid mechanics and one quarter of heat transfer. I teach the thermal systems design course once per year and we have two other instructors that teach the course. The course is taught in the lecture/lab mode: three hours of lecture per week and three hours of lab. The enrollment ranges from fifty to seventy-five students each quarter. The class is split into multiple lecture and lab sections such that the maximum number of students in the lecture and lab are approximately thirty-six and twenty-four, respectively. The lecture content has changed some over the years but the topics and the amount of time spent on each has remained about the same: heat exchangers (20\%), fluid systems (15\%), system modeling and simulation (20\%), economics (20\%), optimization (25\%). The percentages following the topics estimate the amount of time spent on each subject.

Heat exchangers are not covered in the introductory heat transfer course and are a critical component to the design of thermal systems so this subject is covered in the thermal systems design course. We use the same book as the heat transfer class for this component of the class. I also lecture on fluid systems and cover piping system design and pump selection. The students have already been exposed to this in fluid mechanics but pipe frictional losses are introduced in the first fluids class and pumps in the second fluids class and so they don't have many opportunities to put the two together. Also, I think this is an important subject that every mechanical engineering graduate should understand completely. This portion of the class uses their fluid mechanics textbook and additional notes from the lecture. The subjects of heat exchangers and fluid systems (pumps and piping primarily) are subjects that show up in a few of the textbooks on thermal systems design. The depth of coverage for a thermal systems design course will necessarily depend on the context of the curriculum, the intended use in the thermal systems design course and the preferences of the instructor.

The inclusion of system modeling and simulation, economics and optimization is a good fit in a class on thermal systems design. The problem may be to integrate them together in a seamless manner. We started out using a selection of materials from the text by Stoecker ${ }^{8}$. It is an excellent book, however, I found that I did not follow most of what was included in the selections. In my opinion, the economics chapter is too short, the system simulation is not as applied as I would like and the optimization sections are not as up to date given advances in numerical methods and commercial software programs. A significant amount of time is spent on using a structured programming language to solve problems, which may not be as appropriate 
given the wide variety of software applications available for solving engineering problems.

We switched to a custom published book from McGraw-Hill. The book included sections on system simulation and modeling by Suryanarayana and Arici ${ }^{8}$, sections on economics by Blank and Tarquin ${ }^{12}$ and sections on optimization by Jaluria ${ }^{5}$. Again, for various reasons, I was not entirely satisfied with the compilation and decided not to adopt the book again but let the students rely on notes from the lecture. I get similar comments from the students about the class content appearing to be a "hodgepodge" of material and I tend to agree.

For the system modeling and simulation, I typically take a couple different examples and go through the analysis in class. One of the systems we investigate is a solar water heating system. This is a great exercise because it involves the thermodynamic modeling, heat transfer, piping design and head loss calculations, pump selection and sizing, etc. We can then use weather data as input to the model and calculate the transient response. We also model a supercharged engine with an intercooler and simulate the steady-state performance. I would like the students to learn from these examples and be able to model and simulate other systems but the approach to solving other problems can vary dramatically and I have found it is difficult for the students to do this.

Currently, I cover the basics in engineering economics so students can compare the time value of money due to the effects of interest only. After this, we can compare different options and conduct payback and life-cycle cost analyses.

The optimization component of my class focuses more on simple numerical methods for optimization. I cover the Golden Section method and Quadratic approximations for onedimensional optimization problems and steepest descent for multi-dimensional unconstrained optimization. I selected the se one-dimensional methods primarily because they are simple and they are used in Engineering Equation Solver ${ }^{13}$ (EES), which we also use for homework and in the lab. We then investigate various problems with one independent variable such as sizing pipe and selecting pipe insulation thickness based on minimizing cost. I like these examples because they are relevant but pipe diameters and insulation thicknesses come in discrete sizes and so they are not as applicable for an optimization method that assumes a continuous objective function.

\section{Thermal System Design at Cal Poly: Laboratory}

When I started teaching the thermal systems design course at Cal Poly, the laboratory was a computational lab and each week was devoted to solving an individual problem or a group of problems focused on a particular topic. EES was used exclusively and the laboratory topics included: introduction to EES, equation fitting, system simulation, optimization and a term project. The term project was a problem selected from the comprehensive problems in the appendix of the text by Stoecker ${ }^{7}$. While most of the assignments were short problems designed to help the students gain familiarity with the capabilities of EES, some were longer and more applied. There were complaints from students that the problems were just like extended homework problems, which they were. The problems did not seem very design oriented and the students had difficulty seeing the application. The students were not very engaged. 
Considering the feedback from the students, I decided to assign just one lab project for the quarter. The objective of the project was the design of an active solar heating system for domestic hot water (DHW) in the Santa Lucia Dormitory on campus at Cal Poly. A detailed outline of the requirements was provided to the students. The project was broken down into the following phases: solar energy calculations, system selection and design, system simulation and optimization, and economics. The project was conducted in groups of two and the deliverables were a final written report and an oral presentation.

Overall, the project worked well. The students were interested in the project since it involved solar energy and it was concerned with an existing facility on campus. One of the major drawbacks of the project was that if the student groups did something wrong, they didn't know it. Typically, they would put things off until the end and I would not be able to review their work prior to when they submitted their report. There would be one group with a 100 horsepower pump and another with a $1 / 25$ th horsepower pump and they didn't know that something was wrong. They didn't have the experience to spot the problem themselves and there was no other feedback than when I marked it incorrect on the final report. Some of this could be mitigated by requiring the students to turn in something sooner, such as an interim report or project summary.

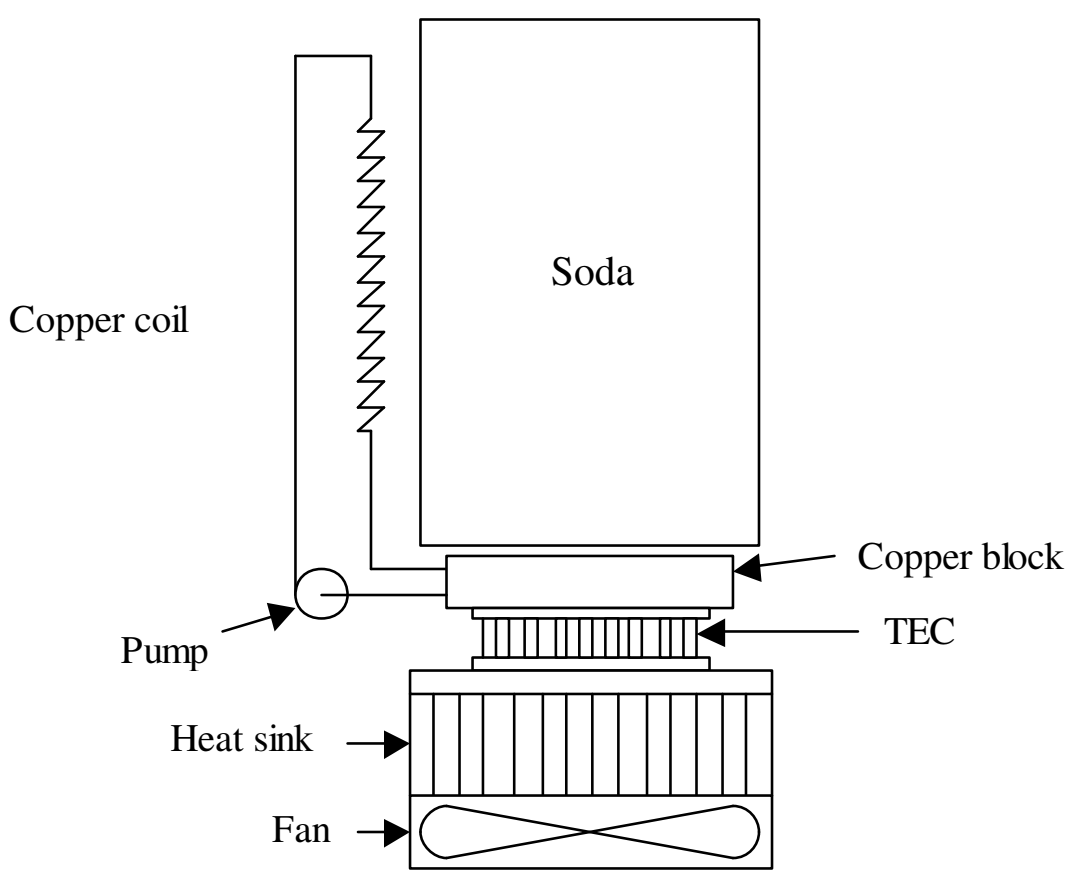

Figure 1. Schematic of soft drink cooler

I decided to try a hardware design project. The objective of the project was to design a device to cool a soft drink using a thermoelectric cooler (TEC). The materials were provided to the students and the basic design was the same for all groups although there was some variation in the models and sizes of the different components. A schematic of the design is shown in Figure 
1. The cold side of the TEC is attached to a copper block with liquid passages. A pump is used to circulate liquid through the copper block where it is cooled and then the cooled liquid passes through a copper coil which is coiled around the soda (shown to side). The hot side of the TEC was attached to a fan/heat sink combination. The TEC, copper block, and fan/heat sink combination were all purchased from Melcor ${ }^{14}$. A windshield washer pump, which normally operates at twelve volts, was operated between three to six volts to circulate the liquid. Design parameters were the model (size) of the TEC, heat sink and fan, the length and diameter of the copper coil and the operating voltage of the pump.

The students were introduced to the operation of the TEC through a series of exercises using EES. For the completed project, students were required to simulate the transient performance of the system as the soft drink was cooled to the required temperature. The analysis consisted of applying the first law of thermodynamics to four separate control volumes, using rate equations to calculate the heat transfer between the control volumes and simulating the transient response using EES.

I like the project because it involves thermodynamics, fluid mechanics, heat transfer, and system simulation. Most of the students enjoyed the project but few were able to satisfy the project requirements to cool the soft drink down to 45 ?F. The heat transfer rates from the cold side of the TEC are typically low, on the order of 10-30 W. Parasitic heat gains were neglected in the simplified analysis but could be significant. Most student teams insulated the soft drink but failed to insulate the transfer lines. In addition, the pump was not very efficient, required about $5 \mathrm{~W}$ of power, most of which was probably transferred to the liquid as a heat gain. The quality of the fabrication varied greatly and many times this was the difference between success and failure. There was insufficient time at the end of the quarter for all the groups to test and debug their designs. Consequently, many of the teams knew that it was not working properly but they could not figure out why.

\section{Conclusions and Recommendations}

After reviewing the textbooks and literature on thermal system design, I realize how difficult it is to decide on a common set of topics for study in the lecture. Different mechanical engineering programs have different starting points and different objectives. Clearly, the computer has changed the way the subject is taught. The availability of commercial software has shifted the emphasis away from students writing their own code to students learning how to use EES or Matlab or another similar program.

For the laboratory, I was surprised to find a mix of both paper design and hardware design projects in the literature. I think both have their utility and can be used effectively. I think we learn from our mistakes, so what mistakes have I made?

a) Sometimes the projects were too complicated and this affected the quality. There is a tendency to put more content in but there is a point where it does not contribute to the course objectives.

b) There was not always sufficient time at the end of the project for evaluation and reflection. Consequently, students made mistakes and they didn't know what went wrong. 
c) Sometimes the class suffered from a lack of structure. There must be a balance between structure and creativity and I think it is more important to sacrifice the creative aspects of the project in order to accomplish course objectives.

\section{References}

1. Genik, Laura J. and Somerton, Craig W., The Use of a Semester Long Theme Problem in a Senior Level Thermal Engineering Course, Proceedings of the 1999 ASEE Annual Conference and Exposition, Charlotte, NC, June 20-23, 1999.

2. Bejan, Adrian, Tsatsaronis, George, and Moran, Michael, Thermal Design and Optimization, $1^{\text {st }}$ ed., John Wiley and Sons, 1996.

3. Boehm, Robert, Design Analysis of Thermal Systems, John Wiley and Sons, 1987.

4. Hodge, B. K. and Taylor, Robert P., Analysis and Design of Energy Systems, $3^{\text {rd }}$ ed., Prentice-Hall, 1999.

5. Jaluria, Yogesh, Design and Optimization of Thermal Systems, McGraw-Hill, 1998.

6. Janna, William S., Design of Fluid Thermal Systems, $2^{\text {nd }}$ ed., Thomson Learning, 1998.

7. Stoecker, W. F., Design of Thermal Systems, $3^{\text {rd }}$ ed., McGraw-Hill, 1989.

8. Suryanarayana, N. V. and Arici, Öner, Design and Simulation of Thermal Systems, McGraw-Hill, 2003.

9. Hodge, B. K. and Taylor, Robert P., The Impact of MathCad in an Energy Systems Design Course, Proceedings of the 1998 ASEE Annual Conference and Exposition, Seattle, WA, June 28 -July 1, 1998.

10. Hodge, B. K. and Steele, W., Computational Paradigms in Undergraduate Mechanical Engineering Education, 2001 ASEE Annual Conference and Exposition, Albuquerque, NM, June 24-27, 2001.

11. Wedekind, Gilbert J. and Kobus, Christopher J., Optimal Design of a Thermal Recuperator, 2001 ASEE Annual Conference and Exposition, Albuquerque, NM, June 24-27, 2001.

12. Blank, Leland T. and Tarquin, Anthony, Engineering Economy, $6^{\text {th }}$ ed., McGraw-Hill, 2005.

13. Engineering Equation Solver, F-Chart Software, 2007.

14. Melcor web site, http://www.melcor.com, viewed on January 17, 2007. 